\title{
Early surgery may lower mortality in patients suffering from severe spinal infection
}

\author{
Sara Lener $^{1}\left(\mathbb{D} \cdot\right.$ Christoph Wipplinger $^{1} \cdot$ Anna Stocsits $^{1} \cdot$ Sebastian Hartmann $^{1} \cdot$ Anja Hofer $^{1} \cdot$ Claudius Thomé $^{1}$
}

Received: 20 March 2020 / Accepted: 20 July 2020 / Published online: 29 July 2020

(C) The Author(s) 2020

\begin{abstract}
Purpose Spinal infection (SI) is a life-threatening condition and treatment remains challenging. Numerous factors influence the outcome of SI and both conservative and operative care can be applied. As SI is associated with mortality rates between 2 and $20 \%$ even in developed countries, the purpose of the present study was to investigate the occurrence and causes of death in patients suffering from SI.

Methods A retrospective analysis was performed on 197 patients, categorized into two groups according to their outcome: D (death) and S (survival). The diagnosis was based on clinical and imaging (MRI) findings. Data collected included demographics, clinical characteristics, comorbidities, infection parameters, treatment details, outcomes, and causes of death.

Results The number of deaths was significantly higher in the conservative group $(n=9 / 51,18 \%)$ compared with the operative counterpart $(n=8 / 146,6 \% ; p=0.017)$. Death caused by septic multiorgan failure was the major cause of fatalities $(n=10 / 17$, $59 \%)$ followed by death due to cardiopulmonary reasons $(n=4 / 17,24 \%)$. The most frequent indication for conservative treatment in patients of group D included "highest perioperative risk" $(n=5 / 17,29 \%)$.

Conclusion We could demonstrate a significantly higher mortality rate in patients solely receiving conservative treatment. Mortality is associated with number and type of comorbidities, but also tends to be correlated with primarily acquired infection. As causes of death are predominantly associated with a septic patient state or progression of disease, our data may call for an earlier and more aggressive treatment. Nevertheless, prospective clinical trials will be mandatory to better understand the pathogenesis and course of spinal infection, and to develop high quality, evidence-based treatment recommendations.
\end{abstract}

Keywords Spinal infection $\cdot$ Spondylodiscitis $\cdot$ Mortality $\cdot$ Infection $\cdot$ Morbidity

\section{Background}

Spinal infection (SI) is a life-threatening condition and defined as an infectious disease affecting the spine and/or the paravertebral tissues [20]. SI may arise primarily by hematogenous spread, or secondarily as a result of spinal surgery or trauma $[3,29]$. The incidence of SI has been increasing as a result of an aging population with serious comorbidities and the rising number of spinal interventions in the last few decades. Additionally, improved diagnostic capabilities have led

This article is part of the Topical Collection on Infection

Sara Lener

sara.lener@i-med.ac.at

1 Department of Neurosurgery, Medical University Innsbruck, Anichstrasse 35, 6020 Innsbruck, Austria to an earlier and more accurate diagnosis $[6,28]$. To date, SI represents 2 to $7 \%$ of all musculoskeletal infections [27]. Early diagnosis of SI is challenging, and adequate treatment is complex, especially in older patients with comorbidities. Conservative treatment options are successful in many cases, but may not suffice. Surgery has to be considered when medical options have failed and symptoms or imaging findings progress. Especially immobilized older patients may benefit from early operative treatment to prevent complications of failed conservative treatment. Numerous factors influence the course and outcome of SI, including age, etiology, severity of comorbidities, as well as the implementation of conservative and operative treatment. Although several guidelines for the treatment of SI are available, therapy is not standardized and is mostly based on individual preferences and experience. SI is still associated with mortality rates between 2 and $20 \%$ in developed countries and is therefore considered a lifethreatening condition $[1,24]$. Thus, the purpose of the present 
retrospective study was to investigate the occurrence and causes of death in patients suffering from SI.

\section{Methods}

We performed a retrospective analysis of all patients presented to our department with an SI between 2010 and 2017. Patients were categorized into two groups according to their outcome: $\mathrm{D}$ (death) and $\mathrm{S}$ (survival). The diagnosis was based on clinical magnetic resonance imaging (MRI) findings and changes in infection parameters. Data was collected using the patients' digital health records (Cerner Millennium - Power Chart, Cerner Corporation 2011, Idstein, Germany) and was documented according to institutional standards and the general standards according to the principles of good clinical practice (GCP). Data included demographics, ASA scores, clinical and neurological characteristics measured by the muscle force assessment (0-5) according to the Medical Research Council (MRC), occurrence of comorbidities, age-adjusted Charlson comorbidity index (ACCI), infection parameters, such as Creactive protein (CRP), treatment details and indications, respectively (operative vs. conservative), and treatment outcomes as well as causes of death. Sepsis was defined by the presence of two or more systemic inflammation response syndrome (SIRS) criteria. Patients suffering from (1) neurological deficits, (2) progressive or intractable pain, and/or (3) radiological progression due to MRI findings despite maximum conservative treatment qualified for surgical treatment, after being medically cleared for surgery by an interdisciplinary team. The operative procedure was determined individually for each patient, depending on present comorbidities, the extent and location of the infection, and the grade of vertebral destruction. All patients were additionally treated with intravenous broad-spectrum antibiotics (primarily clindamycin and ciprofloxacin, adjusted to the antibiogram whenever available) [12].

\section{Statistical analysis}

All patients with complete initial data were considered for inclusion in the retrospective analysis. Values are expressed by mean \pm standard deviation (SD). The KolmogorovSmirnov test was used for testing normal distribution. The unpaired Student's $t$ test and Mann-Whitney $U$ test were performed to analyze differences in clinical and demographic characteristics and in clinical outcome variables. Frequencies were compared by the Chi-square and Fisher's exact tests. Spearman's rho correlation (r) was determined to assess the relationship between clinical outcome and demographics. A $p$ value $<0.05$ was considered statistically significant. All statistical evaluations were performed with SPSS version 21.0 (IBM Corp. Released 2012. IBM SPSS Statistics for Mac
OS X, version 21.0, NY: IBM Corp.). Figures were designed using Microsoft Excel (version 15.36 for Mac OS X, Microsoft Corporation 2017, Redmond, USA).

\section{Results}

\section{Baseline characteristics}

One hundred ninety-seven patients with a sufficient data set were identified and evaluated retrospectively. Overall mortality in our cohort was $8.6 \%(n=17 / 197)$. Demographic details and patients' characteristics are outlined in Table 1. Twentytwo (11.2\%) patients suffered from isolated discitis or isolated spondylitis, respectively. One hundred thirty-six patients (69.0\%) were diagnosed with spondylodiscitis, whereof 64 $(47.1 \%)$ presented with an accompanying spinal epidural abscess (SEA) and 48 (35.3\%) with an additional paravertebral abscess. Moreover, $6.1 \%(n=12 / 197)$ of patients showed an isolated SEA without affection of the discs or vertebral bodies, whereas 5 patients $(2.5 \%)$ presented with an isolated paravertebral abscess.

\section{Management}

Fifty-one patients $(25.9 \%)$ were treated conservatively, and 146 patients $(74.1 \%)$ were managed surgically. Depending on the extent of infection and bony destruction, surgical cases were only decompressed or decompressed and instrumented with or without (partial) corpectomy (Table 2). A CT-guided biopsy was performed initially in 35 patients (17.8\%), and in 24 thereof $(68.6 \% ; 12.2 \%$ of the entire cohort), a pathogen could be detected. The most commonly isolated pathogen was multi-sensitive Staphylococcus aureus $(n=5 / 24$, $20.8 \%$ ). An antibiogram-adjusted antibiotic treatment due to a positive pathogen detection was conducted in $41.2 \%(n=7 /$ 17) of patients in group $\mathrm{D}$ and in $28.8 \%(n=52 / 180)$ of patients in group $\mathrm{S}(p>0.05)$ (Fig. 1).

\section{Causes of death}

The majority of patients (59\%) died from septic multiorgan failure $(n=10 / 17)$, followed by death due to cardiopulmonary reasons $(n=4 / 17,24 \%)$. Death by septic multiorgan failure was significantly more frequent in the conservatively treated group $(n=6 / 17 ; 35 \%)$ when compared with the surgically treated patients $(n=4 / 17 ; 24 \% ; p<0.05)$. The individual causes of death for both treatment groups are depicted in detail in Fig. 2. Reasons for the indication of a solely conservative treatment scheme in group D patients included "highest perioperative risk" $(n=5 / 17,29 \%)$, "no neurological deficit" $(n=3 / 17,18 \%)$, and "healing of abscesses before intervention" $(n=1 / 17,6 \%)$. These 
Table 1 Demographic details

\begin{tabular}{|c|c|c|c|c|}
\hline & & Group $\mathrm{D} n=17$ & Group S $n=180$ & \\
\hline Age & In years $(S D)$ & $71.2( \pm 9.6)$ & $65.1( \pm 12.4)$ & n.s. \\
\hline \multirow[t]{2}{*}{ Sex, $n(\%)$} & Male & $9(52.9)$ & $122(67.8)$ & n.s. \\
\hline & Female & $8(47.1)$ & $58(32.2)$ & \\
\hline BMI & In kg/m2 (SD) & $29.8( \pm 13.1)$ & $25.9( \pm 4.6)$ & n.s. \\
\hline \multirow[t]{4}{*}{ ASA score, $n(\%)$} & ${ }^{\circ} 1$ & $0(0.0)$ & $16(8.9)$ & $p<0.01$ \\
\hline & ${ }^{\circ} 2$ & $1(5.9)$ & $52(28.9)$ & \\
\hline & $\circ 3$ & $12(70.6)$ & $102(56.7)$ & \\
\hline & ${ }^{\circ} 4$ & $4(23.5)$ & $10(5.6)$ & \\
\hline \multirow[t]{2}{*}{ Etiology, $n(\%)$} & Primary & $14(82.4)$ & $113(62.8)$ & n.s. \\
\hline & Secondary & $3(17.6)$ & $67(37.2)$ & \\
\hline \multirow[t]{2}{*}{ Treatment, $n(\%)$} & Operative & $8(47.1)$ & $138(76.7)$ & $p<0.05$ \\
\hline & Conservative & $9(52.9)$ & $42(23.3)$ & \\
\hline \multirow[t]{2}{*}{ Abscess, $n(\%)$} & Epidural & $4(23.5)$ & $60(33.3)$ & n.s. \\
\hline & Paravertebral & $4(23.5)$ & $44(24.4)$ & \\
\hline \multirow[t]{6}{*}{ Location of infection, $n(\%)$} & Cervical & $2(11.8)$ & $22(12.2)$ & n.s. \\
\hline & Thoracic & $5(29.4)$ & $32(17.8)$ & \\
\hline & Lumbar & $9(52.9)$ & $107(59.4)$ & \\
\hline & $\begin{array}{l}\text { Cervical and } \\
\text { thoracic }\end{array}$ & $0(0.0)$ & $2(1.1)$ & \\
\hline & $\begin{array}{l}\text { Cervical and } \\
\text { lumbar }\end{array}$ & $0(0.0)$ & $1(0.6)$ & \\
\hline & $\begin{array}{l}\text { Thoracic and } \\
\text { lumbar }\end{array}$ & $1(5.9)$ & $16(8.9)$ & \\
\hline $\begin{array}{l}\text { Total number of comorbidities, } \\
\text { (SD) }\end{array}$ & & $2.4( \pm 1.4)$ & $1.7( \pm 1.3)$ & $p<0.05$ \\
\hline \multirow[t]{7}{*}{ Type of comorbidities, $n(\%)$} & Depression & $3(17.6)$ & $15(8.3)$ & n.s. \\
\hline & Renal failure & $9(52.9)$ & $24(13.3)$ & $p<0.01$ \\
\hline & Diabetes & $7(41.2)$ & $33(18.3)$ & n.s. \\
\hline & Heart disease & $10(58.8)$ & $62(34.4)$ & n.s. \\
\hline & Vascular disease & $9(52.9)$ & $71(39.4)$ & n.s. \\
\hline & Hepatopathy & $5(29.4)$ & $30(16.7)$ & n.s. \\
\hline & Dental disease & $0(0.0)$ & $8(4.4)$ & n.s. \\
\hline \multirow[t]{2}{*}{ Cancerous disease, $n(\%)$} & Active disease & $2(11.8)$ & $10(5.6)$ & n.s. \\
\hline & Status post & $2(11.8)$ & $14(7.8)$ & n.s. \\
\hline \multirow[t]{3}{*}{ Noxae, $n(\%)$} & Smoking & $0(0.0)$ & $31(17.2)$ & n.s. \\
\hline & Alcohol abuse & $1(5.9)$ & $13(7.2)$ & n.s. \\
\hline & Drug abuse & $3(17.6)$ & $23(12.8)$ & n.s. \\
\hline \multirow[t]{3}{*}{ Blood culture, $n(\%)$} & Positive & $7(41.2)$ & $40(22.2)$ & n.s. \\
\hline & Staph. aureus & $5(29.4)$ & $15(8.3)$ & $p<0.01$ \\
\hline & other & $3(17.7)$ & 21 (11.6) & n.s. \\
\hline
\end{tabular}

( $n$ population, $S D$ standard deviation)

indications justifying conservative treatment differed significantly between groups $\mathrm{D}$ and $\mathrm{S}(p \leq 0.01)$. When rated as "highest perioperative risk" and treated conservatively, a patient's chance to survive was $50 \%(n=5 / 10)$. When treated conservatively due to missing neurologic symptoms, a survival rate of $92.3 \%$ was observed $(n=36 / 39)$. Indications for operatively treated patients in group D solely included "progression of symptoms" ( $n=8 / 17,47 \%)$.
Individual treatment indications in both groups are shown in detail in Table 3.

\section{Factors contributing to outcome}

A higher mortality was observed in patients treated conservatively $(n=9 / 51,18 \%)$ compared with surgically treated patients $(n=8 / 146,6 \% ; p=0.017$; Fig. 1$)$. This was also the 
Table 2 Details of operative treatment for both groups

\begin{tabular}{|c|c|c|c|c|}
\hline & & Group D $n=8$ & Group S $n=138$ & \\
\hline Operative time & In minutes $(S D)$ & $264( \pm 108)$ & $188( \pm 89)$ & $p<0.05$ \\
\hline \multirow[t]{3}{*}{ Operation performed cervical, $n(\%)$} & Corpectomy and fusion & $2(25.0)$ & $7(5.1)$ & n.s. \\
\hline & Fusion & $1(12.5)$ & $28(20.3)$ & \\
\hline & Decompression & 0 & $5(3.6)$ & \\
\hline \multirow[t]{3}{*}{ Thoracic, $n(\%)$} & Corpectomy and fusion & $3(37.5)$ & $4(2.9)$ & \\
\hline & Fusion & 0 & $19(13.8)$ & \\
\hline & Decompression & 0 & 0 & \\
\hline \multirow[t]{3}{*}{ Lumbar, $n(\%)$} & Corpectomy and fusion & 0 & $7(5.1)$ & \\
\hline & Fusion & $2(25.0)$ & $66(47.8)$ & \\
\hline & Decompression & 0 & $2(1.4)$ & \\
\hline Ventral approach, $n(\%)$ & & $3(37.5)$ & $25(18.1)$ & n.s. \\
\hline Dorsal approach, $n(\%)$ & & $5(62.5)$ & $113(81.9)$ & \\
\hline
\end{tabular}

( $n$ population, $S D$ standard deviation)

case in patients classified with ASA 3 or higher (conservatively treated: $n=8 / 32,25 \%$ vs. operatively treated: $n=8 / 96,8 \%$; $p<0.01)$. Overall, patients in group $\mathrm{S}$ demonstrated a significantly lower ASA score (mean: $2.6 \pm 0.7$ ) when compared with group D (mean: $3.2 \pm 0.5 ; p \leq 0.01$ ). Duration of surgery differed significantly between group $\mathrm{S}(188 \pm 89 \mathrm{~min})$ and group $\mathrm{D}(264 \pm 108 \mathrm{~min} ; p=0.031)$. The overall time interval from diagnosis to death in group D was $110 \pm 294$ days, whereas the time from surgery to death was $43 \pm 60$ days.

The occurrence of an epidural or a paravertebral abscess was not associated with higher mortality $(p>0.05)$. The total number of accompanying illnesses per patient differed significantly between both groups (S: $1.7 \pm 1.3$ vs. D: $2.4 \pm 1.4 ; p=$ $0.019)$. The ACCI also demonstrated significantly worse scores in group $\mathrm{D}(6.5 \pm 2.3)$ than in group $\mathrm{S}(3.8 \pm 2.3$; $p<0.01)$. A higher mortality was shown for patients suffering from renal failure (S: $n=24 / 180,13 \%$ vs. D: $n=9 / 17,53 \%$; $p \leq 0.01)$ and diabetes mellitus (DM) tended to be associated with a higher mortality rate as well $(p=0.071)$. Group D largely consisted of patients affected by primary acquired spondylodiscitis $(n=14 / 17,82.4 \%)$ compared with group $\mathrm{S}$ $(n=113 / 180,62.8 \%)(p>0.05)$. Group D showed significantly higher CRP levels (D: $23.1 \pm 12.9 \mathrm{mg} / \mathrm{dl}$ vs. S: $10.9 \pm$ $11.1 \mathrm{mg} / \mathrm{dl} ; p=0.01$ ) and signs of sepsis at admission (D: $n=13 / 17,76.5 \%$ vs. S: $n=38 / 180,21.1 \% ; p \leq 0.01)$. Also, patients in group $\mathrm{D}$ were admitted with significantly more pronounced neurological deficits, measured by the weakest muscle group according to the MRC (S: $3.9 \pm 1.5$ vs. D: 1.7 $\pm 1.8 ; p=0.002$ ). In group $\mathrm{S}$, neurological deficits as well as infection parameters, improved significantly during the
Fig. 1 Mortality in patients treated operatively vs. conservatively. (n: population, D: death, S: survival)

$$
\begin{aligned}
& \text { operatively treated patients } \\
& \qquad(n=145)
\end{aligned}
$$

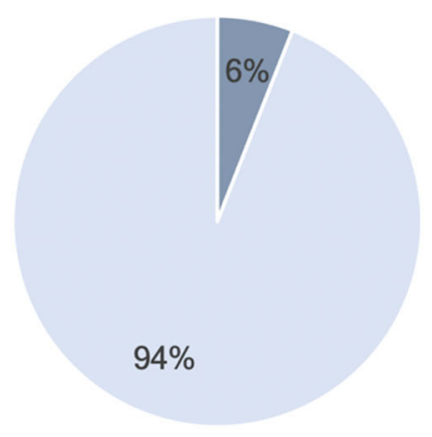

- Group D Group S conservatively treated patients $(n=51)$

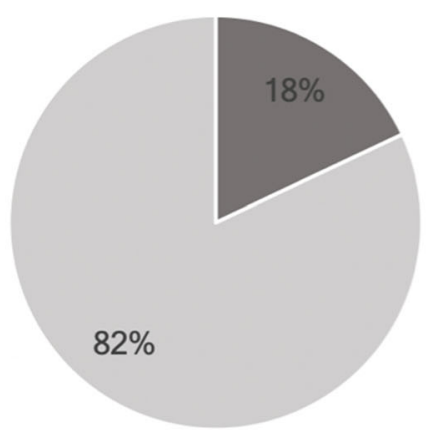

$p<0.05$

- Group D $\approx$ Group S 
Fig. 2 Causes of death in operatively vs. conservatively treated patients causes of death

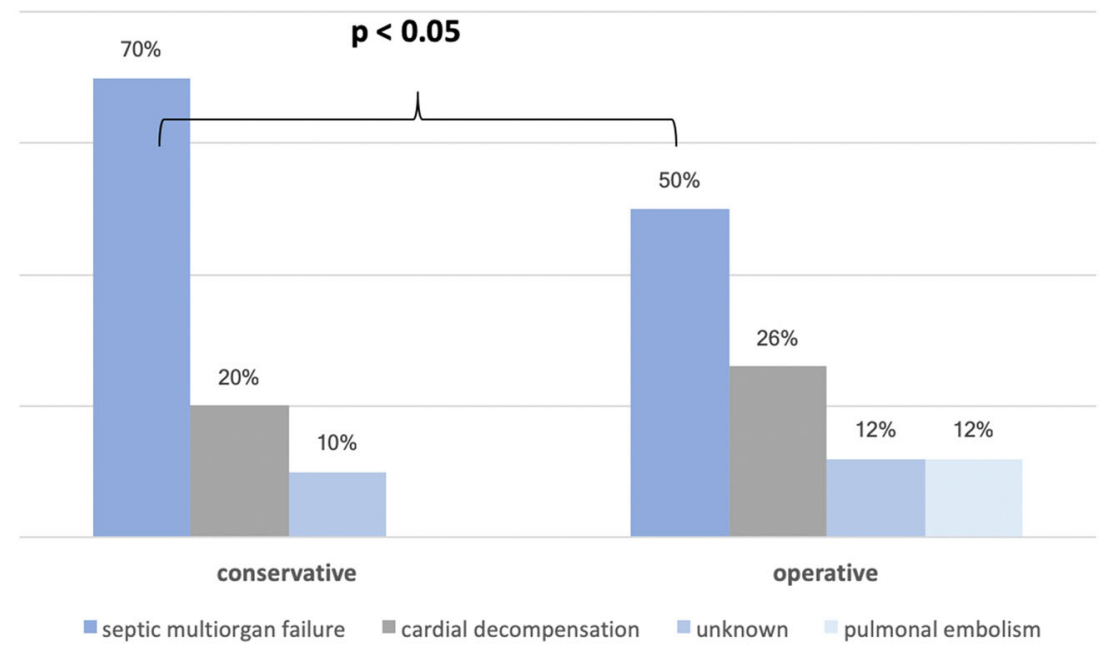

hospital stay $(p<0.05)$ whereas in group D parameters tended to improve over time, but this failed to reach statistical significance $(p>0.05)$.

\section{Discussion}

We report the results of a retrospective analysis investigating the relevant factors for mortality in spinal infections. Deceased patients were more frequently affected by primary acquired spondylodiscitis, and patients died significantly more often under conservative treatment compared with the surgical counterpart. Two thirds of patients died from septic multiorgan failure followed by death due to cardiopulmonary reasons. Indications for solely conservative treatment in patients who died included "highest perioperative risk," "no neurological deficit," and "prior healing of abscesses," whereas reasons for surgical intervention were limited to "progression" for this particular patient group.

Table 3 Individual treatment indications for both, conservative and operative treatment

\begin{tabular}{lcc}
\hline & Group D & Group S \\
\hline $\begin{array}{l}\text { Reasons for conservative treatment } \\
\text { Highest perioperative risk }\end{array}$ & $29 \%$ & \\
No neurological deficit & $18 \%$ & $1 \%$ \\
Other prior treatment indicated & $5 \%$ & $22 \%$ \\
Reasons for operative treatment & & $1 \%$ \\
Progressive disease & $18 \%$ & $57 \%$ \\
Pain & $12 \%$ & $17 \%$ \\
Paraplegia & $18 \%$ & $2 \%$ \\
\hline
\end{tabular}

The course of primarily acquired SI may be more severe than that of postoperatively acquired SI [29]. A higher mortality of primarily acquired SI was observed in our retrospective analysis; however, it failed to reach statistical significance. Our data did not show any correlation of a para/ epidural abscess with mortality. Still, primarily acquired spondylodiscitis was more likely to be associated with a paravertebral or an intraspinal abscess [29]. Previous data revealed that the higher mortality and a more severe course of primarily arisen SI may be linked to a more frequent occurrence of abscesses, which could not be demonstrated in our cohort. A preexisting compromised immune status of affected patients would be plausible as other underlying reason for the serious course of primarily acquired SI.

It is widely known that renal failure is associated with a higher mortality in infection and septic shock $[16,26]$. Furthermore, it may not only show validity in primary infection but also in postoperatively occurring infections. Mortality in secondary acquired SI was shown to be nearly three times higher when accompanied by chronic renal failure [18, 21]. Underlying reasons include that kidney failure and uremia are associated with severe alterations of the immune system, as the mechanisms required for complete activation of $\mathrm{T}$ cells are compromised $[8,22,30]$. Moreover, in chronic kidney disease, the neutrophil count may not be altered, but neutrophils are less capable to eradicate microorganisms [17]. The occurrence of DM showed a trend to be correlated with higher mortality. In our cohort, however, this finding failed to reach statistical significance. Nevertheless, special attention should be paid to patients suffering from DM and presenting with SI, as DM is a known risk factor for surgical site infection as well as for the development of septic shock. Thus, patients with $\mathrm{DM}$ and an $\mathrm{HbA} 1 \mathrm{c}$ above $7.5 \%$ are not scheduled for elective spine surgery at the authors' department. This goes in line 
with the literature threshold of Hbalc $\geq 7.0 \%[5,9,14]$. Overall, the total number of patients' comorbidities and a subsequently higher ASA score seemed to be a predictive factor for increased mortality when affected by an SI. Several measurements to evaluate the impact of comorbidities and the estimation of morbidity and mortality have been designed to evaluate and grade the degree of comorbidity burden, one of them being the ACCI [4]. It is known to be a reliable parameter to predict mortality in various disease patterns and especially in bacteremia [15]. It has been reported that Charlson score $>3$ to $>6$ is predictive for developing severe sepsis, both postoperatively and primarily acquired [10, 13, 19]. A similar correlation could be shown in previous studies, in which a preoperative ASA $>2$ led to significantly increased death rates in patients treated with spinal instrumentation [24]. Compared with our cohort, this may also be true for patients being treated for SI.

Treatment strategies for SI still remain controversial and the implementation of the optimal therapy for each patient needs to be individualized. Conservative cases seem to be followed by mechanical low back pain more often than surgical cases and develop more deformity in the long term. This appears particularly true for cervical cases, in which an infectious kyphosis often represents the final stage of SI [23]. To overcome this drawback by surgery comes at a price, as complication rates are higher in surgically treated cases. Overall mortality, however, is lower in operated patients [28]. Even multimorbid patients at an advanced age may show better overall outcomes when treated surgically, despite an increased risk of perioperative complications. It has been shown that delayed surgical treatment entails significantly poorer surgical outcome $[2,7]$. In their analysis of 34,465 patients, Segreto et al. clearly demonstrated that delayed surgery is associated with increased mortality and complication rates [25]. Thus, it has been favored to indicate early surgery even in sick and comorbid patients.

The overall mortality in our cohort was $8.6 \%$ and is comparable with recently reported rates between 2 and $20 \%$ in developed countries [1,24]. Patients died significantly more often when treated conservatively, which substantiates the aforementioned opinions. If patients were not considered appropriate candidates for surgery due to "highest perioperative risk," i.e., they presented in a poor general clinical condition, they had a $50 \%$ risk to die. According to the available literature, this may well surpass the perioperative risk, particularly if treated early after onset of symptoms. Therefore, when it comes to decide whether a conservative or an operative strategy should be performed, the potential risk of surgery outweighing the risk of death due to a surgically untreated septic shock has to be taken into strong consideration. Furthermore, the whole team including anesthesia should be aware of significantly higher mortality rates in patients not operated, especially when scored with ASA 3 or higher. In particular, septic multiorgan dysfunction was the most frequently reported reason for death in our cohort, even significantly more common in the conservatively treated patient group. The second most frequent cause of death was cardiopulmonary issues (i.e., cardiac decompensation, respiratory insufficiency, pulmonary embolism) which may also be related to the septic status of the patients. As a result, this leaves room for discussion if the focus on the infection, which in those cases with great probability caused death by septic multiorgan dysfunction, should at least potentially be extracted. This subsequently increases the patients' chance of survival as it aims to remove the primary focus of infection.

The indications for medical treatment in group D differed significantly compared with the surviving patients cohort, with the surviving majority of patients mostly being treated conservatively because of a missing neurological deficit, but not due to the level of systemic inflammatory symptoms. Furthermore, surgically treated patients only died if the indication for surgery was "progression of symptoms." Patients were treated medically until the disease was clinically and radiologically progressive and surgery had to be performed urgently. As mentioned before, delayed surgical treatment is already known to lead to a significantly poorer outcome in patients with SI $[2,7]$.

When managed surgically, patients who suffered death showed significantly longer operation times, consistent with a higher number of fused levels, as infection may have broadly spread. It is known that longer operative time might be associated with a higher mortality $[11,24]$. Nevertheless, in our cohort, it is presumed that the operative time may play a subordinate role, and that the extension and severity of infection may be decisive for the patients' outcome. Additionally, patients at a higher risk for surgical treatment with progressive SI might benefit from a reduced length of operation.

\section{Limitations}

The main limitation of our study is its retrospective nature. There obviously is selection bias, as many SI patients do not even reach a supraregional referral center and are managed successfully with conservative care. Nevertheless, if patients fail conservative care, show progressive symptoms, or develop neurologic deficits, they will be transferred to our university hospital. Thus, our results are representative for this more severely affected subpopulation of SI patients.

Additionally, indication of surgery may vary according to the attending neurosurgeon, anesthesiologic triage, patient will, and expectations. Overall, however, literature data as well as our results suggest that delayed surgery increases mortality. Special attention should be paid on quickly identifying and managing comorbidities (i.e., renal failure, diabetes mellitus), especially in multimorbid patients. Although further 
prospective studies are mandatory, early surgery seems to be beneficial in severely affected SI patients.

\section{Conclusion}

Spinal infection is a serious and life-threatening disease requiring urgent treatment. Our retrospective analysis demonstrates a significantly higher mortality rate in patients receiving solely conservative treatment. Mortality is frequently associated with number and type of comorbidities, but also trends to be correlated with primarily acquired infection. As causes of death are predominantly associated with a septic patient state or progression of disease, our data may call for an earlier and more aggressive treatment. Nevertheless, prospective clinical trials will be mandatory to better understand the pathogenesis and course of spinal infection and to develop high quality, evidence-based treatment recommendations.

Funding Information Open Access funding provided by University of Innsbruck and Medical University of Innsbruck.

\section{Compliance with ethical standards}

Conflict of interest CT receives speaker honoraria and grant research support from medical implant companies. All other authors certify that they have no affiliations with or involvement in any organization or entity with any financial interest (such as honoraria; educational grants; participation in speakers' bureaus; membership, employment, consultancies, stock ownership, or other equity interest; and expert testimony or patent-licensing arrangements), or non-financial interest (such as personal or professional relationships, affiliations, knowledge, or beliefs) in the subject matter or materials discussed in this manuscript.

Ethical approval For this type of study, ethical approval is not required.

Abbreviations ASA, American Society of Anesthesiologists; CRP, Creactive protein; $D$, Death; $D M$, Diabetes mellitus; $G C P$, Good clinical practice; $M R I$, Magnetic resonance imaging; $S$, Survival; $S D$, Standard deviation; SI, Spinal infection

Open Access This article is licensed under a Creative Commons Attribution 4.0 International License, which permits use, sharing, adaptation, distribution and reproduction in any medium or format, as long as you give appropriate credit to the original author(s) and the source, provide a link to the Creative Commons licence, and indicate if changes were made. The images or other third party material in this article are included in the article's Creative Commons licence, unless indicated otherwise in a credit line to the material. If material is not included in the article's Creative Commons licence and your intended use is not permitted by statutory regulation or exceeds the permitted use, you will need to obtain permission directly from the copyright holder. To view a copy of this licence, visit http://creativecommons.org/licenses/by/4.0/.

\section{References}

1. Aagaard T, Roed C, Dahl B, Obel N (2016) Long-term prognosis and causes of death after spondylodiscitis: a Danish nationwide cohort study. Infect Dis 48(3):201-208

2. Alton TB, Patel AR, Bransford RJ, Bellabarba C, Lee MJ, Chapman JR (2015) Is there a difference in neurologic outcome in medical versus early operative management of cervical epidural abscesses? Spine J 15(1):10-17

3. Calhoun JH, Manring MM (2005) Adult osteomyelitis. Infect Dis Clin North Am 19(4):765-786

4. Charlson M, Szatrowski TP, Peterson J, Gold J (1994) Validation of a combined comorbidity index. J Clin Epidemiol 47:1245-1251

5. Carton JA, Maradona JA, Nuño FJ, Fernandez-Alvarez R, PérezGonzalez F, Asensi V (1992) Diabetes mellitus and bacteraemia: a comparative study between diabetic and non-diabetic patients. Eur J Med 1(5):281-287

6. Corrah TW, Enoch DA, Aliyu SH, Lever AM (2011) Bacteraemia and subsequent vertebral osteomyelitis : a retrospective review of 125 patients. QJM. 104(3):201-207

7. Curry WT Jr, Hoh BL, Amin-hanjani S, Eskandar EN (2005) Spinal epidural abscess : clinical presentation , management, and outcome. Surg Neurol 63(4):364-371

8. Diekema DJ, Beekmann SE, Chapin KC, Morel KA, Munson E, Doern GV (2003) Epidemiology and outcome of nosocomial and community-onset bloodstream infection. J Clin Microbiol 41(8): $3655-3660$

9. Dubory A, Giorgi H, Walter A, Bouyer B, Vassal M, Zairi F et al (2014) Surgical-site infection in spinal injury: incidence and risk factors in a prospective cohort of 518 patients. Eur Spine J 24(3): 543-554

10. Eskesen AN, Astrup Belle M, Blomfeldt A (2018) Predictors of one-year all-cause mortality and infection-related mortality in patients with Staphylococcus aureus bacteraemia. Infect Dis 50(10): 743-748

11. Fei Q, Li J, Lin J, Li D, Wang B, Meng H et al (2016) Risk factors for surgical site infection after spinal surgery: a meta-analysis. World Neurosurg 95:507-515

12. Fleege C, Wichelhaus TA, Rauschmann M (2012) Systemic and local antibiotic therapy of conservative and operative treatment of spondylodiscitis. Orthopade. 41(9):727-735

13. Hampshire PA, Guha A, Strong A et al (2011) An evaluation of the Charlson co-morbidity score for predicting sepsis after elective major surgery. Indian J Crit Care Med 15(1):30-36

14. Hikata T, Iwanami A, Hosogane N, Watanabe K, Ishii K, Nakamura $\mathrm{M}$ et al (2014) High preoperative hemoglobin A1c is a risk factor for surgical site infection after posterior thoracic and lumbar spinal instrumentation surgery. J Orthop Sci 19(2):223-228

15. Lesens $\mathrm{O}$ et al (2003) Role of comorbidity in mortality related to Staphylococcus aureus bacteremia: a prospective study using the Charlson weighted index of comorbidity. Infect Control Hosp Epidemiol 24:890-896

16. Maizel J, Deransy R, Dehedin B, Secq E, Zogheib E, Lewandowski $\mathrm{E}$ et al (2013) Impact of non-dialysis chronic kidney disease on survival in patients with septic shock. BMC Nephrol 14:77

17. McClelland E, Smith JM (2011) Gender specific differences in the immune response to infection. Arch Immunol Ther Exp 59:203213

18. Minakata K, Bando K, Tanaka S, Takanashi S, Konishi H, Miyamoto $\mathrm{Y}$ et al (2014) Preoperative chronic kidney disease as a strong predictor of postoperative infection and mortality after coronary artery bypass grafting. Circ J 78(9):2225-2231

19. Mokart D, Leone M, Sannini A et al (2005) Predictive perioperative factors for developing severe sepsis after major surgery. Br J Anaesth 95(6):776-781 
20. Nickerson EK, Sinha R (2016) Vertebral osteomyelitis in adults: an update. Br Med Bull 117(1):121-138

21. Puvanesarajah V, Jain A, Hess DE, Shimer AL, Shen FH, Hassanzadeh H (2016) Complications and mortality after lumbar spinal fusion in elderly patients with late stage renal disease. Spine (Phila Pa 1976) 41(21):E1298-E1302

22. Rebelo M, Pereira B, Lima J, Decq-Mota J, Vieira JD, Costa JN (2011) Predictors of in-hospital mortality in elderly patients with bacteraemia admitted to an internal medicine ward. Int Arch Med 4(1):33. https://doi.org/10.1186/1755-7682-4-33

23. Rutges JP, Kempen DH, van Dijk M, Oner FC (2016) Outcome of conservative and surgical treatment of pyogenic spondylodiscitis: a systematic literature review. Eur Spine J 25(4):983-999

24. Schoenfeld AJ, Wahlquist TC (2015) Mortality, complication risk, and total charges after the treatment of epidural abscess. Spine J [Internet]. Elsevier Inc 15(2):249-255. Available from:. https://doi. org/10.1016/j.spinee.2014.09.003

25. Segreto FA, Beyer GA, Grieco P, Horn SR, Bortz CA, Jalai CM, Passias PG, Paulino CB, Diebo BG (2018) Vertebral osteomyelitis: a comparison of associated outcomes in early versus delayed surgical treatment. Int J Spine Surg 12(6):703-712

26. Shmuely H, Pitlik S, Drucker M, Samra Z, Konisberger H, Leibovici L (2000) Prediction of mortality in patients with bacteremia: the importance of pre-existing renal insufficiency. Ren Fail 22(1):99-108

27. Sobottke R, Röllingho M, Zarghooni VK, Zarghooni K, Delank KSK, Seifert H et al (2010) Spondylodiscitis in the elderly patient : clinical mid-term results and quality of life. Arch Orthop Trauma Surg 130(9):1083-1091

28. Stuer C, Stoffel M, Hecker J, Ringel F, Meyer B (2013) A staged treatment algorithm for spinal infections. J Neurol Surg A Cent Eur Neurosurg 74(2):87-95

29. Tschugg A, Lener S, Hartmann S, Rietzler A, Neururer S, Thomé C (2017) Primary acquired spondylodiscitis shows a more severe course than spondylodiscitis following spine surgery : a singlecenter retrospective study of 159 cases. Neurosurg Rev [Internet]. Neurosurgical Review; Available from:. https://doi.org/10.1007/ s10143-017-0829-9

30. Weinstein MP, Reller LB, Murphy JR, Lichtenstein KA (1983) The clinical significance of positive blood cultures: a comprehensive analysis of 500 episodes of bacteremia and fungemia in adults. I Laboratory and epidemiologic observations. Rev Infect Dis 5(1): $35-53$

Publisher's note Springer Nature remains neutral with regard to jurisdictional claims in published maps and institutional affiliations. 